\title{
Monthly Estimates of the Quantum of Fertility: Towards a Fertility Monitoring System in Austria $^{1}$
}

\author{
Tomáš Sobotka, Maria Winkler-Dworak, Maria Rita Testa, Wolfgang \\ Lutz, Dimiter Philipov, Henriette Engelhardt, and Richard Gisser"
}

\begin{abstract}
Short-term variations in fertility and seasonal patterns of childbearing have been of interest to demographers for a long time. Presenting our detailed study of period fertility in Austria since 1984, we discuss the problems and advantages of constructing and analysing monthly series of various period fertility indicators that reflect real exposure and potentially minimise the distortions caused by changes in fertility timing. We correct monthly birth data for calendar and seasonal factors and show that seasonality of births in Austria varies by birth order. Our study suggests that most of the timing distortions can be eliminated when using an indicator derived from the period parity progression ratios based on birth interval distributions, termed the "period average parity" $(P A P)$. We illustrate the insights gained with the $P A P$ and compare this with the commonly used total fertility rates in an analysis of the recent upswing in period fertility, starting in the late 2001. This investigation will be useful in establishing a monitoring of monthly fertility rates in Austria.
\end{abstract}

\section{Introduction}

Observing variation constitutes the primary source of information about the determinants of change. This holds for our everyday learning as well as for much of the natural and social sciences. The three dimensions along which we observe variation in behaviour - the inter-individual, the spatial and the temporal dimension - taken together, provide us with a rich set of empirical data from

\footnotetext{
1 This article contains a number of supplementary resources in the form of Appendices which are not included in the printed volume of the Vienna Yearbook of Population Research but are posted on the Yearbook's Internet page (http://www.oeaw.ac.at/vid/yearbook/).

* Vienna Institute of Demography, Vienna, Austria. Author for correspondence: Tomáš Sobotka, Vienna Institute of Demography, Prinz-Eugen-Strasse 8, $2^{\text {nd }}$ floor, A-1040, Vienna, Austria. Email: tomas.sobotka@oeaw.ac.at
} 
which we can derive plausible hypotheses about the reasons for this differential behaviour and the drivers of change that can also be extrapolated into the future.

Demographic analysis typically is carried out along all three dimensions. But at different times and in various schools of demographic research the weights placed on these dimensions differ. Traditional macro-level demography almost exclusively studied change and variation at the level of populations, as the word demography (derived from the Greek demos $=$ people and graphein $=$ to write) implies. More recently, thanks to the advance of statistical methods and the availability of large data sets collected through sample surveys, the research emphasis has strongly shifted toward the individual level, trying to disentangle the reasons for differential behaviour in population subgroups through multivariate analysis. Even more recently the study of individual biographies (life course analysis) also introduced the dimension of temporal change into the analysis, thus opening a broad and previously untapped field of research. The time steps considered in these life course studies are now typically calendar months because years turned out to be too crude a time unit.

But the analysis of individual-level variation cannot tell us the full story. In order to understand the reasons of differential behaviour we also need to consider its societal context. Different welfare regimes, labour market patterns, cultural values, norms and public sentiments all present important macro-level determinants of demographic behaviour. Typically, these questions have been considered at the level of countries but more recent attempts to capture the contextual variables have gone much further along this path to characterising the contexts of demographic behaviour in smaller areas, combining the individual level with aggregate-level analysis. Temporal variation has remained the most important source of information at the macro-level, but the unit of temporal analysis has almost exclusively been the calendar year. The main reason for this prominent focus on annual variations is probably the availability of data, which are typically published and often collected on an annual basis.

From a theoretical point of view one might assume that a smaller, i.e., more precise unit of temporal variation would provide us more information about the nature of the process under study. At the level of individual life course analysis the transition from annual to monthly data has long been made. Why should not a similar transition be made for the analysis of aggregate demographic data?

This is the issue this article aims to address. Presenting our detailed study of period fertility in Austria since 1984, we discuss the problems and advantages of analysing monthly data and constructing monthly period fertility indicators that are not only free of seasonality effects but also minimise the distortions caused by changes in the timing of childbearing. Such analysis is useful for a precise allocation of the shifts and trend reversals in fertility rates as well as for studying seasonal and cyclical patterns in fertility. The former is particularly important in times of substantial social and economic changes, when fertility rates may change suddenly from one month to another. The extreme events of the $20^{\text {th }}$ century, such 
as wars, social upheavals, economic crises and famines, had a profound effect on fertility, which can best be traced with short-term indicators. Legislative changes related to abortion in Central and Eastern Europe were frequently translated into pronounced twists in fertility, with a time-lag allowing for completion or termination of pregnancies that had already been under way (e.g., David 1999). ${ }^{2}$ Political regime change can also have strong impact on fertility rates: in the former GDR, the collapse of the state-bureaucratic system, symbolised by the fall of the Berlin wall and the subsequent German unification, had a pronounced effect on period fertility, which dropped to extreme low levels. ${ }^{3}$ Less marked shifts in fertility might be linked to the ups and downs of the business cycle or to changes in family-related policies. Since some of the contextual variables change from month to month, there is a great potential gain from a transition to monthly data. Such data permit more precise inferences concerning the factors affecting fertility. In the Austrian context, studying monthly trends in period fertility is particularly useful for analysing changes in relevant social security and child benefit policies but also, in a broader perspective, changes in widespread feelings and public sentiments. One could also get a better handle on perception lags and reaction times to such changes.

Short-term variations in fertility and seasonal patterns of childbearing have been of interest to demographers for a long time and a variety of hypotheses have been postulated on the biological, cultural, environmental, and social determinants of birth seasonality in various historical and contemporary settings (e.g., Lam, Miron, and Riley 1994; Doblhammer-Reiter, Rodgers, and Rau 1999; Bobak and Gjonca 2001). Nevertheless, seasonal cycles constitute an obstacle for assessing short-term trends in period fertility. Especially in low-fertility settings, changes in the registered monthly number of births may capture the attention of the media and the general public. Thus, it is important to disentangle seasonal variation and the real increase in fertility rates. An advanced analysis of monthly fertility rates was developed by G. Calot (e.g., Calot and Nadot 1977; Calot 1981a and 1981b). Although most statistical offices publish only raw data on the observed monthly number of births, at least one- the Office of National Statistics for England and Wales - publishes both crude and seasonally adjusted monthly total fertility rates in its birth statistics yearbook (ONS 2004).

Our investigation of monthly fertility in Austria goes several steps further than the existing studies. We calculate fertility rates for each birth order separately, using the usual total fertility rates as well as the exposure-specific

2 The most notorious example is the case of Romania, where a severe restriction of the access to abortion effective from October 1966 resulted in a sharp increase of the monthly birth rate per 1000 women to 38.7 in July 1967, representing an increase by a factor of 2.7 in comparison with the birth rate of 14.3 recorded in July 1966 (David 1970). Conversely, after the regime change and the legalisation of abortion in Romania since December 1989, the period total fertility rate fell from 2.06 to 1.50 between May and August 1990 (Sardon 1998).

3 Following the unification in October 1990, the total fertility rate in East Germany fell below 1.0 since April 1991 and reached the record-low level of 0.77 in 1993-94 (Sardon 1998). 
rates and fertility table indicators. To our knowledge, birth order (parity) has rarely been considered in the studies on birth seasonality (Prioux 1988 and Haandrikman 2004 being notable exceptions) and parity-specific fertility indicators have never been constructed on a monthly basis. In addition, we also analyse the possibilities of eliminating the distortions in period fertility rates caused by changes in the timing of childbearing. The practical outcome of our endeavours is the establishment of a monthly monitoring system providing a database of the most recent fertility indicators in Austria, which will be updated regularly with the latest birth records obtained from Statistics Austria.

The remaining parts of this paper are structured as follows. First, we discuss tempo distortions in period fertility and the existing methods that aim to eliminate these distortions. Then we specify the data and methods employed and introduce different indicators analysed. Section 5 discusses selected general findings on birth seasonality and the analysis of monthly fertility data. Subsequently, Section 6 provides a comparative analysis of the fertility indicators studied. The following section uses most recent data to illustrate the insights gained with monthly fertility indicators. Section 8 discusses the advantages and potential deficiencies of the fertility indicator based duration-parity life table model, termed 'period average parity,' which we use extensively in our analysis. The last section concludes.

\section{Tempo Distortions in Period Fertility Rates}

Commonly used indicators of period fertility, such as the period total fertility rate (TFR), are sensitive to the changes in the timing of childbearing. When women advance or postpone childbearing, total fertility rates do not reflect the "pure" level (quantum) of period fertility, but rather an interplay of the quantum and timing influences, the latter often being referred to as tempo effects. These timing shifts do not affect the completed cohort fertility rate which constitutes an unambiguous indicator of fertility quantum. A shift towards a later timing of childbearing, which is currently underway in almost all European countries, pushes the period total fertility rates towards lower levels than would be observed if the timing of childbearing remained stable. In other words, since the younger generations of men and women wait increasingly longer before entering parenthood, a considerable proportion of births is perpetually postponed towards the future. This process is reflected by a divergence between the period total fertility rates, which are deflated by tempo effects, and the completed cohort fertility rates. For instance, the mean value of the period TFR in Austria in 19841990 was 1.46 , well below the estimated completed fertility among women born in 1960 (1.77), who had realised a substantial portion of their childbearing during 
that period. These contrasts between the period and the cohort TFR are particularly strong in the case of first births (Sobotka 2004a). ${ }^{4}$

The issue of timing distortions has received much attention since 1998, when Bongaarts and Feeney proposed an adjustment of the period TFR based on orderspecific total fertility rates and annual changes in the order-specific mean age at childbearing. At least three different factors have contributed to the subsequent rapidly evolving debate on tempo effects. First, many Northern and Western European countries have experienced more than three decades of continuous fertility postponement - which is a very long period of one-directional shift in fertility timing when compared with other timing shifts during the last century. ${ }^{5}$ Second, countries representing more than half of the European population have experienced a decline of the period TFR to extreme low levels of 1.1-1.3 (Sobotka 2004b). In this context, the question whether such low fertility levels are attributable to distortions caused by fertility postponement or whether they reflect alarmingly low levels of fertility quantum appears crucial. While the latter possibility would justify calls for explicit pronatalist interventions, the first possibility reflects a growing need for detailed assessment on the magnitude of tempo distortions in period fertility and the possible extent of the future increase in the period TFR. Third, Bongaarts and Feeney offered a relatively simple method of period fertility adjustment, which can be readily used in the majority of European countries.

The debate on timing effects in period fertility indicators and the BongaartsFeeney adjustment in particular has proceeded in several main directions. On a general level, many contributions have addressed the issue of delayed parenthood and its impact on fertility level and trends (e.g., Lesthaeghe and Willems 1999; Frejka and Calot 2001; Lesthaeghe 2001; Philipov and Kohler 2001; Bongaarts 2002; Kohler, Billari, and Ortega 2002; Ní Bhrolcháin and Toulemon 2003; Sobotka 2004a) as well as on the long-term population dynamics (Lutz, O'Neill, and Scherbov 2003; Goldstein, Lutz, and Scherbov 2003). From a methodological perspective, the Bongaarts-Feeney method has been repeatedly criticised for its unrealistic assumptions ${ }^{6}$ (e.g., van Imhoff and Keilman 2000; Schoen 2004) and,

4 While the mean value of the first-order TFR in Austria in 1984-1990 (0.668) seemingly indicates that about one third of women might eventually remain childless, the estimated level of final childlessness among women born in 1962 is only at a half of this value, namely 16 to $17 \%$.

5 Austria has been no exception to a Europe-wide trend of delayed parenthood, although there the process started somewhat later than in most Western European countries. In the early 1980s a typical Austrian woman gave birth to her first child before reaching age 24 . Since then, the mean age at first birth among women in Austria (calculated from the age schedule of incidence rates) has increased by more than three years, reaching 27 years in 2004 (see Figure AN-1 in Annex).

6 The main objections to the Bongaarts-Feeney formula are as follows: (1) It assumes that the age shape of the fertility schedule remains constant over time, i.e., that all cohorts postpone or advance childbearing to the same extent. (2) It is based on order-specific incidence rates ('reduced' rates) which do not take into account the actual parity distribution of the female 
from the practical point of view, for the occasional erratic values and considerable fluctuations in the adjusted period TFR.

Further development of the more sophisticated methods of period fertility adjustment was a logical outcome of the criticism of the Bongaarts-Feeney method. Kohler and Philipov (2001) suggested an adjustment which additionally incorporates changing variance in the age-specific schedule of incidence rates, while Kohler and Ortega (2002) and Yamaguchi and Beppu (2004) proposed an adjustment of the exposure-specific fertility indicators. A different approach was advocated by Schoen (2004), who employed completed cohort fertility data to derive an indicator of period fertility that is free of tempo distortions. Nevertheless, only limited attention has been paid to examining the usefulness of other existing indicators in reflecting the fertility level during the periods marked by substantial shifts in fertility timing; the analysis presented by Toulemon (2001 and 2004) constitutes the main exception.

This article assesses the usefulness of parity-specific fertility indicators constructed within the life table framework, especially those based on the duration-parity model, in constituting a workable alternative to the period total fertility rate. Our explicit aim is to propose an indicator that is sufficiently stable when used on a monthly basis and at the same time capable of eliminating most of the tempo distortions typical of the TFR. Our investigation reveals that this aim can be reasonably attained using a fertility index based on parity and duration since the previous birth, termed here "period average parity" $(P A P)$.

\section{Data}

Our study requires highly disaggregated data which are not commonly tabulated on a monthly basis. Statistics Austria supplied us with extracts from individual birth records in 1984-2004, which allowed us to construct any of the existing indicators of period fertility. We draw on data on all live-born children in Austria between January 1984 and November 2004, consisting of 1.8 million records. The variables used are the date of birth of mother and child, biological live birth order of each child, and the date of the last previous birth that serves for a computation of birth interval (duration) analysis. The collection of birth statistics pertaining to the real (biological) birth order of a child started in Austria only in 1984 and therefore our analysis could not be extended to the period before 1984, when most of the fertility decline following the baby boom of the 1960s took place.

population by age. As a result, the adjusted $T F R$, when specified by birth order, is often distorted by changes in the parity distribution among women as much as the ordinary period $T F R$. Furthermore, it can be shown that the period mean age at childbearing, calculated from the age and order-specific incidence rates, is itself an imperfect indicator of change in fertility timing (Sobotka 2004a: 74-75), which may also contribute to the instability of results provided by the Bongaarts-Feeney adjustment. 
Estimating the denominator (female population at risk) required combining different data sources. As the population by age and parity cannot be derived from a population register, these data had to be derived by combining the 1991 Census data on age and parity distribution among women (Statistics Austria 1996) with our continually updated monthly estimates of age and order-specific fertility rates and the annual time series on the number of women by age, taken from EUROSTAT (2004). For the more recent time series starting from January 2001 we updated our estimates with the 2001 Census results (Statistics Austria 2005). More details on the estimation procedure are provided on the Internet in Appendix 2. We performed a sensitivity analysis to test whether our updated recent age-parity estimates based on the 2001 Census produce different values of the age-parity fertility table indicator $(P A T F R)$ than the original estimates based on the 1991 Census and found relatively minor differences, which did not create any obvious break in the time series of fertility rates (see Appendix 5). Finally, to compute fertility indicators based on duration since the previous birth, we had to estimate the distribution of live births by birth order for the years prior to 1984 . Data for 1961-1979 were derived from retrospective data on the distribution of births by birth order as recorded in the 1981 Census (Statistics Austria 1989) combined with the total registered number of live births in that period. The number of live births by birth order in 1980-1983 was estimated from the total number of live births and the relative distribution of order-specific births in 19781979 and 1984-1985.

\section{Methods}

\subsection{Seasonal and Calendar Adjustment of Raw Number of Births}

Analysing the monthly number of births requires calendar and seasonal adjustments. The reason for the calendar corrections is that different numbers of weekdays within a month and different lengths of the months within a year may alter the final amount of monthly births. Indeed, as shown in previous work (Calot 1981b; Höhn 1981; Gisser 1984), births occur more frequently on working days than at weekends (see also Figure AN-2 in the Annex), and moreover, differences in the monthly number of births are influenced by the different number of days in a given month. Seasonal corrections are necessary for a proper interpretation of seasonal patterns in births and become prerequisites for a more advanced analysis of fertility trends.

We compute a corrected monthly number of births by using the following adjustment:

$$
C B_{i}(a)=B_{i}(a) \cdot I_{C} \cdot I_{S i},
$$


where $B_{i}(a)$ represents the observed number of births of birth order $i$ by the age of mother $a, C B$ denotes the corrected number of births; $I_{C}$ is the calendar factor, and $I_{S i}$ denotes the seasonality fluctuations of births of order $i$.

To estimate the calendar factor we compute the weekday coefficients. These coefficients are given by the average daily number of births of the particular weekday divided by the mean number of births per day. Births are more frequent on Mondays to Fridays, irrespective of birth order. ${ }^{7}$ As the differences by birth order were not significant, we did not include birth order components in the calendar adjustment.

Then, the calendar factor is derived by summarising over the distribution of weekdays within the month, which are weighted by the corresponding weekday coefficient. ${ }^{8}$ Note that the calendar factor can be decomposed into two parts: an effect which can be linked to the length of the month, and a net effect for each day of the week (Ladiray and Quenneville 2001). The net effect only involves days of the week occurring five times in a month. Since every month contains four complete weeks, their net effects cancel out, and only the net effects of the additional days are controlled for. ${ }^{9}$ Finally, the calendar factor standardises the monthly number of births to $1 / 12$ of the year. Computations of the weekday coefficients, as well as the statistical tests, were performed using the statistical software package STATA (StataCorp 2004).

Seasonal adjustments are aimed at removing seasonal variations from the time series. There are numerous methods for the adjustment of seasonal variation; a useful review is provided by Ladiray and Quenneville (2001). We use the X-12ARIMA method implemented in the software package Gretl (Cottrell 2004). This method, developed by the US Bureau of the Census (Findley et al. 1998), is an iterative seasonal adjustment algorithm based on ratio-to-moving averages and is similar to the method proposed by Calot (1981a) for the seasonal adjustment of births. However, the X-12-ARIMA differs from the Calot's method in that the future values are forecasted by the use of ARIMA models (following the BoxJenkins method) and the extended series is seasonally adjusted in order to increase stability at the end of the time series.

We find that the seasonal pattern is rather stable over the whole investigation period, but unlike the calendar factor, the seasonality in births varies by birth order (see Section 5.1). Hence, we perform the seasonal adjustment of the monthly number of births separately for birth orders 1,2 , and $3+$.

The figures of the weekday coefficients by birth order in 2003 can be found in Figure AN-2 in the Annex; Appendix 1 specifies in detail the decomposition of the calendar adjustment factor.

8 Since the birth records of 2004 utilised here are not complete, we used the weekday coefficients derived from 2003 to correct the monthly number of births from January 2004 to November 2004.

9 I.e., the net effect of one additional day for a February in a leap year, two additional days for April, June, September, and November, and three additional days for January, March, May, July, August, October and December remains. 


\subsection{The Selection of Fertility Indicators Analysed in this Study}

Since the changes in fertility timing make the interpretation of the total fertility rate highly problematic, any credible analysis of recent fertility trends should consider the distortions caused by fertility postponement. At the same time, the issue of how to correct period fertility indicators for these distortions remains disputed and none of the methods proposed thus far provides an unambiguous indicator of period fertility quantum. No research undertaken in the past has studied tempo distortions in shorter intervals than annual time series. Although from a purely theoretical viewpoint there is no difference in tempo effects between annual and monthly data, the use of explicit adjustment methods requires additional data manipulation in the latter case. We were facing a number of obstacles when deriving the monthly fertility indicators. Besides extensive data requirements, the computation of various fertility indicators by calendar month implied that the age and parity structure of the female population had to be estimated by calendar month as well. In order to test whether using more detailed birth data would change the resulting fertility rates, we also investigated the differences between monthly fertility rates specified by single years of age of women (annual birth cohorts) and the rates calculated for monthly birth cohorts (see Section 5.2).

This study puts the main emphasis on parity-specific indicators that reflect real exposure and on indicators that potentially minimise the distortions caused by the changes in fertility timing. A parity-specific approach is consistent with the sequential nature of childbearing and approximates the family-building behaviour of real cohorts much closer than the usual approach based on incidence rates (Lutz 1989). Specifically, the life table (or 'fertility table') model constitutes our preferred framework to analyse period fertility. All indicators considered here are based on the synthetic cohort approach. The total quantum of fertility is expressed in terms of the mean number of children per woman, which is an intuitively understandable and easily interpretable unit of measurement. The aggregate total fertility quantum can be decomposed by birth order. To allow a compact and readable overview of various methods and indicators analysed, we kept the use of equations and symbols at the minimum level. A complete overview of all the equations used is provided in Appendix 3. 


\subsection{Fertility Indicators Selected for the Analysis}

Our study analyses the following indicators of period fertility:

\section{The total fertility rate (TFR)}

Despite its shortcomings, this most widely used indicator of period fertility constitutes a starting point of our analysis as well as a benchmark to compare other fertility indicators.

\section{The fertility index based on age and parity life table (PATFR)}

Although not frequently used, a multistate fertility table based on age and parity is the most established parity-specific method of period fertility analysis. For any given period, fertility behaviour is specified by the set of age and parity-specific birth probabilities (or occurrence-exposure rates). Starting from the age when all women are childless (in our analysis age 12) this model generates for every age a parity distribution that corresponds to the schedule of age-parity birth probabilities in a given period. The final parity distribution of the synthetic cohort of women at the end of their reproductive period (age 50 in our analysis) can be summarised in the overall fertility index PATFR (this acronym follows Rallu and Toulemon (1994), who termed the PATFR an index controlling for parity and age).

Parity progression ratios based on duration since previous birth (parity and duration life table model, PPRd)

In this framework, the transition rate between different parities is a function of the time elapsed since the previous birth. As contrasted with the PATFR index specified above, duration (birth interval) rather than the actual age is seen as a main parameter of fertility behaviour among women having at least one child. For each parity, a summary indicator combining fertility rates across all the birth intervals considered gives the period parity progression ratio $(P P R d)$.

This study scrutinises two types of duration-parity indicators. For the whole period of 1984-2004, we compute duration-specific 'incidence rates,' which relate births of order $i$ in the period $t$ at duration $d$ to the initial number of women who experienced birth of order $i-1$ in the period $t-d$. Exposure is based solely on the time series of the total number of live births specified by birth order. We compute the period parity progression ratios for each parity above 0 as a sum of orderspecific incidence rates for all durations (birth intervals) considered, namely 0 to 25 years. This method is an analogy to duration-specific incidence rates, pioneered by L. Henry to analyse marital fertility (e.g., Henry 1961). For the period starting in 1999, we also construct duration-parity birth probabilities based on the distribution of the female population by parity status and the year of 
previous birth for each calendar month considered. ${ }^{10}$ Both methods were described by Rallu and Toulemon (1994); we provide a more detailed overview of our estimation of the exposure population in Appendix 2 and of the computation of duration-parity variables in Appendix 3.

Our estimates of the population of women by parity and the year of previous birth do not account for the influence of mortality and migration. Especially the 'zero migration' assumption is problematic: since the late 1980s, Austria has become an immigration society and immigration certainly affects the numbers of women by parity and duration since the previous birth. Having no data on the parity and birth interval distribution of migrant women, we decided to ignore the possible effects of migration. ${ }^{11}$ Based on previous research, we expect that the exposure-based model will provide more stable results than the model based on 'incidence rates,' which depicted stronger fluctuations in the case of France (Rallu and Toulemon 1994) and the former GDR (Barkalov and Dorbritz 1996). To distinguish between parity progression ratios based on duration-based incidence rates and those based on duration-parity birth probabilities, we denote the former as PPRdIR, whereas the latter are termed PPRd.

\section{The period average parity (PAP)}

The duration-parity model specified above cannot be applied for first births. However, two different approaches are methodologically compatible with this framework to derive the fertility index of birth order 1 and consequently also the overall total fertility. Traditionally, the parity progression method has been used to analyse marital fertility and the date of marriage then served as a starting point of exposure to first birth (e.g., Henry 1953; Feeney and Yu 1987). Alternatively, first birth duration may be seen as a function of age. Then, the parity progression ratio to a first birth is given by the age and parity model specified above. This is a clearly preferable option for analysing fertility changes in any advanced society, since the high rates of non-marital childbearing imply that the study of marital fertility has become obsolete as it captures only a portion of the aggregate fertility. A combination of the PATFR index for birth order 1 with the parity-progression ratios to second and later births based on duration (birth intervals) yields the summary index of period fertility, which we call period average parity $(P A P) .{ }^{12}$

10 Our detailed time series of parity-specific birth data start only in 1984. To estimate the number of women by parity and the year of previous birth, we aimed to cover a sufficiently long 'exposure' period, in this case at least 15 years (1984-1998). As a result, we computed all the duration-parity birth probabilities only from 1999 onwards.

11 As a result, our estimates of parity progression ratios are probably slightly above the "correct" values, which would reflect the real exposure population. While the numerator (number of births) is complete in our computations, the denominator-number of women by current parity and the year of previous birth-is underestimated, resulting thus in higher values of derived indicators of fertility.

12 There is no established way to term this summary indicator. Feeney and $\mathrm{Yu}$ (1987), for instance, simply use the term TFR or "parity progression ratio TFR", while Rallu and Toulemon (1994) 
Although deriving the $P A P$ index is a data-intensive endeavour, it has one considerable advantage: it is less affected by changes in fertility timing than the other (non-adjusted) period fertility indicators. Although its first component, the PATFR index of parity 1 , is distorted by the timing changes, it is free of the distortions caused by the shifting parity composition of the female population, which strongly affect the period TFR for first births. This parity composition effect is also apparent in Austrian data (see Section 6.2 and Figure 4). Assuming that the trend towards later timing of childbearing is primarily driven by the postponement of first births and the subsequent pace of childbearing remains relatively constant, duration-based parity progression ratios should be little affected by tempo effects. We provide further discussion on the usefulness of the period average parity in minimising tempo effects in period fertility and expressing thus correctly fertility quantum in Section 8.

Besides these indicators, we also investigated the possibility of computing monthly fertility rates using methods that provide explicit adjustment for changes in fertility timing. In particular, we focused on the method by Bongaarts and Feeney (1998), incorporating in addition state space smoothing as proposed by Kohler and Ortega (2002). Due to size limitations, these results are not included in this article, but we intend to report on them separately in the future. However, the adjustment proposed by Kohler and Ortega (2002) is used here for the overall evaluation of results depicted on an annual basis; its use is restricted to birth orders 1 and 2 (see Appendix 3, Section A-3.6 for more details).

\section{Analysing Monthly Birth Data and Fertility Rates: General Findings}

This section summarises general findings from our analysis of monthly birth data. The next section then provides an assessment of different fertility indicators studied.

\subsection{Birth Seasonality Differs by Birth Order}

The seasonal pattern of childbearing remained stable during the analysed period, with a peak in summer and early fall and a trough in the last quarter of the year. In line with Prioux (1988) and Haandrikman (2004), our analysis reveals that this profile is not equal for different birth orders. We illustrate these differences in

refer to the "index of parity and duration since previous birth" $(P D T F R)$ and, in the particular case of duration-specific incidence rates, to the "duration-specific incidence rates index" $(P D i T F R)$. We propose the term period average parity $(P A P)$ in order to distinguish this index clearly from the commonly used total fertility rates, to emphasise its derivation from the period parity progression ratios and at the same time to keep the name reasonably short. 
Figure 1, which displays monthly seasonal indexes of births by birth order between December 2002 and November 2004. While there are fewer births of orders 1 and 3+ in spring (especially in April and May), births of order 2 occur more often in spring; the mean seasonal coefficient for 1984-2004 is by $2 \%$ above the average monthly level in March and April (Figure AN-3 in Annex). Furthermore, the peak in September is more pronounced for first births than for higher parities (coefficients 1.07 versus 1.04).

However, the causes of the parity-specific differences of the seasonality in births are less clear. Prioux (1988) finds that the seasonal variation of first births in the 1960s and 1970s can to some extent be traced back to the seasonal variation in marriage planning, and thus partly explains the differences in seasonality

\section{Figure 1:}

Seasonal coefficients of the monthly number of births by birth order from December 2002 to November 2004

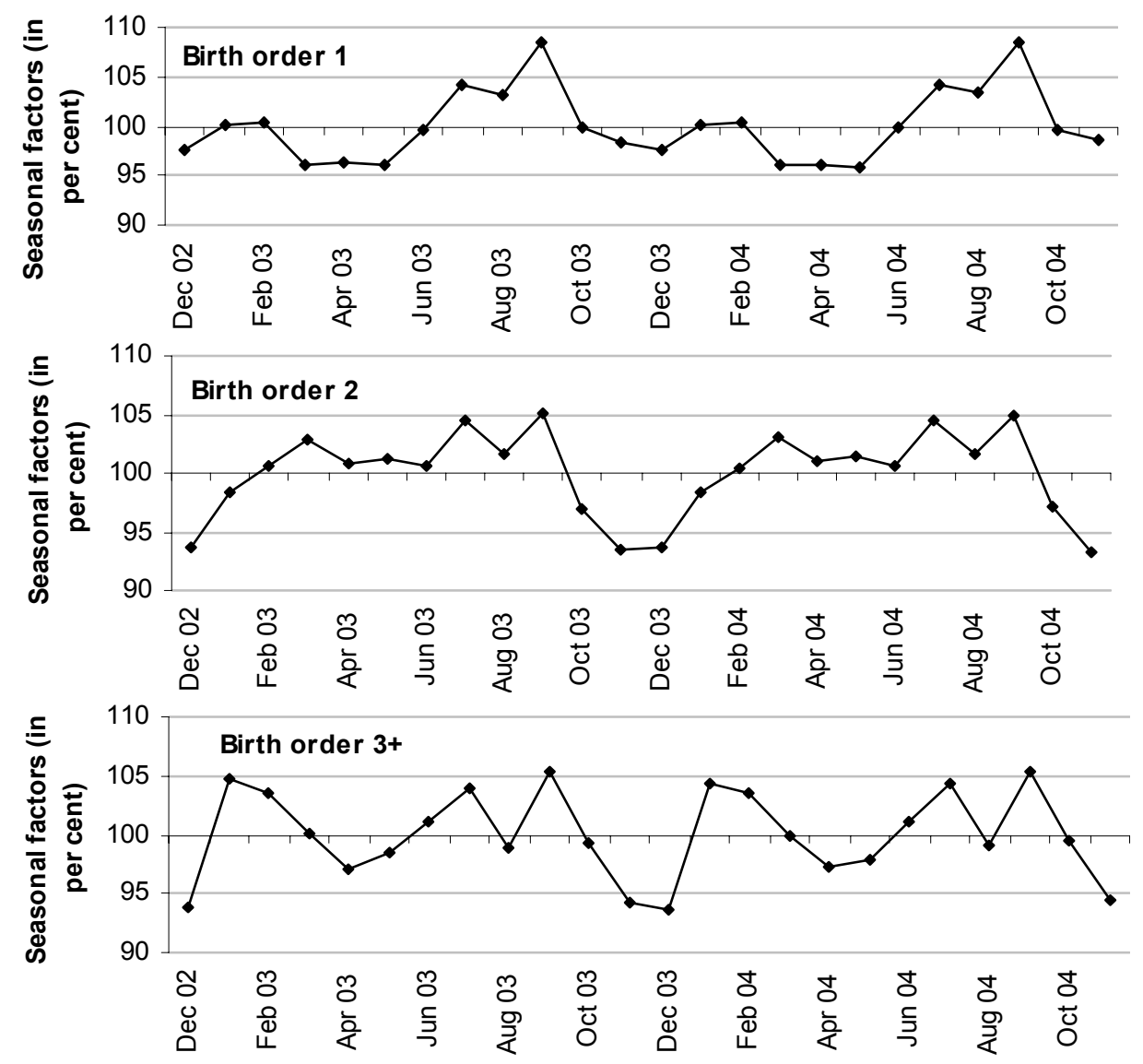


between first and higher-order births during these periods. But there is less evidence on the influence of seasonality of marriages in more recent times. Haandrikman (2004) proposes that the seasonality differences by birth order may be partly due to parity-specific differences in the planning of births. Moreover, due to the availability of efficient contraceptives, some of the factors which influence the seasonality of births may affect the specific birth order to a different extent. For instance, the "holiday effect", which links the higher number of births in September to the Christmas and New Year holidays (Doblhammer-Reiter, Rodgers, and Rau 1999), may have a stronger impact on first births, where both partners are most probably working before having a child. This would explain the more pronounced September peak for first births. In addition, Prioux (1988) finds that second births are more planned than other birth orders. This may possibly explain why Austrian second births occur more frequently in spring, while first, third and higher-order births display a trough in these months. However, a more thorough analysis is required. We intend to study parity differences in the seasonal pattern of fertility in Austria more in depth in our subsequent work.

\subsection{Considering Monthly Birth Cohorts does not Alter the Resulting Fertility Indicators}

Seeking to derive as precise estimates as possible, we calculated all the orderspecific incidence rates, the total fertility rates and the mean ages at childbearing from month-cohort data as well as in the usual age cohort format defined by single years of age. Using the detailed monthly data, specified for ages 132 to 612 months (ages 11 to 51 in completed years), did not bring any detectable change in the resulting order-specific fertility indicators. Due to the small number of births in each category, the monthly age-specific rates were extremely erratic when computed for monthly birth cohorts, whereas the aggregate indexes of fertility were identical with those derived from rates specified by single years of age. As a result, we did not pursue the computations of rates by monthly birth cohorts any further and used the annual birth cohorts of women aged 12 to 50 to derive all age-specific fertility indicators. Considering monthly birth cohorts also did not alter the indicators of fertility timing, namely mean and median age of mother at childbearing. Appendix 4 provides further details on our comparisons of the month-cohort and year-cohort age data formats. 


\subsection{Raw Data and Crude Fertility Rates Display Considerable Monthly Variation}

Figure 2 compares monthly numbers of live births with the crude period total fertility rate and with the TFR adjusted for both calendar and seasonality factors. Within the seasonal adjustment algorithm of the X12 ARIMA method, the trend component is estimated that eliminates the irregular component from the analysed data. The gross TFR is characterised by strong irregularities and therefore is not suitable for an evaluation of monthly trends. Similar or even stronger fluctuations are typical of order-specific gross total fertility. Clearly, seasonal factors and short-term distortions play an important role and the monthly time series of period fertility can be meaningfully analysed only after the adjustment for calendar, seasonal, and irregular components is applied. ${ }^{13}$ In the following parts of this article, we focus on fertility trends net of the seasonal and irregular influences and present all the indicators adjusted for calendar and seasonality components. ${ }^{14}$

Figure 2:

Monthly series of live births, crude $T F R$, and the $T F R$ adjusted for calendar factors and seasonalitv in 1984-2004

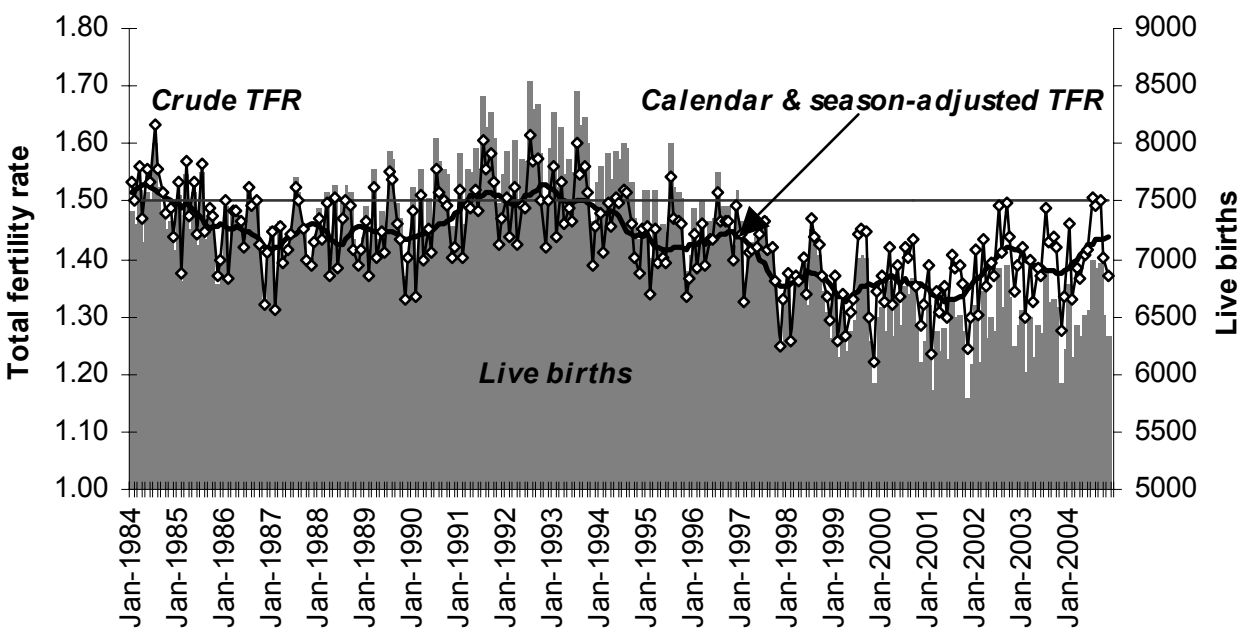

13 One remarkably stable feature of seasonality patterns of fertility in Austria is the elevated fertility in the third quarter of the year, between July and September. While the differences between the mean gross TFR in the first, second, and fourth quarter are often indistinguishable, the total fertility rate in the third quarter always stands out, although the magnitude of this difference varies over time. The average third-quarter $g$ TFR in 1984-2003 was 1.49 as contrasted with 1.43 in the first quarter, 1.42 in the second quarter, and 1.39 in the fourth quarter (see Figure AN-4 in Annex).

14 To maintain consistency between our order-specific fertility estimates and the overall TFR, we calculated the overall calendar- and season-adjusted total fertility by aggregating the orderspecific TFRs. The differences between this estimate and the direct adjustment of the overall TFR were negligible, on average only $0.3 \%$ in relative terms. 


\section{Comparing Various Fertility Indicators}

\subsection{Total Fertility Rates by Birth Order}

Viewed from the perspective of long-term trends, the total fertility rate in Austria shows low but stable levels over the whole period of observation, with a mean value of 1.43. This stability is particularly apparent for the TFR of birth order 2, which oscillates very close to the level of 0.50 and to a large extent also for the first-order $T F R$, which typically reaches values between 0.65 and 0.70 (see Figure 3 ). Only the total fertility of orders 3 and higher is an exception from this stability: it generally tended to decline, although gradually, thus mirroring the secular trend towards the smaller family size. The decline in higher-order TFR ceased between 1986 and 1992 and, more importantly, there have been signs of a trend reversal starting in October 2001 (see also Section 7). It is only in the most recent years that the order-specific components of total fertility have generally moved in the same direction.

\section{Figure 3:}

Total fertility rate by birth order between January 1984 and November 2004

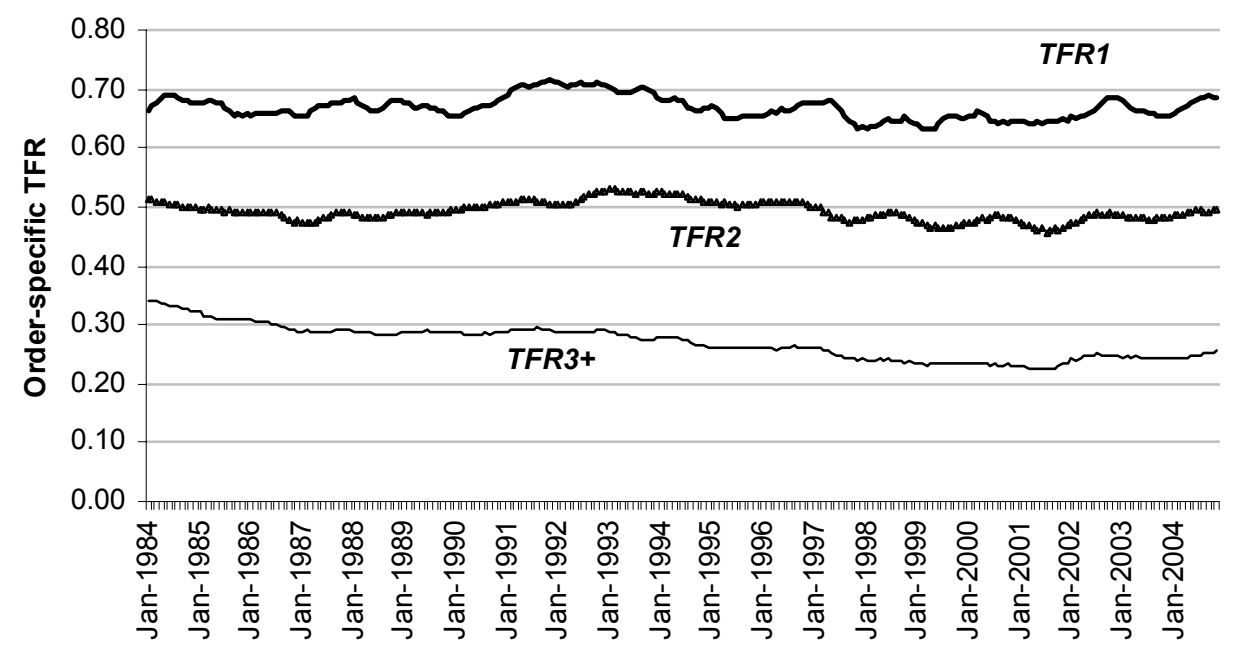




\subsection{The Fertility Index Based on Age and Parity Life Table (PATFR)}

The PATFR index, which is free of the distortions caused by shifting parity distribution of women, differs considerably from the TFR in the case of first birth order (see Figure 4). ${ }^{15}$ It shows very narrow irregularities over time and does not display clearly detectable peaks and troughs, which are, at least to a limited extent, present in the period TFR. However, the general trends are in agreement between both indicators, showing a slightly increasing tendency in the most recent years. Over the whole observation period, between January 1984 and November 2004, the first-order PATFR was on average by 0.10 higher $(0.767)$ than the first-order TFR (0.669). This is a considerable difference, which shows

Figure 4:

The period PATFR by birth order as compared with the TFR, 1984-2004

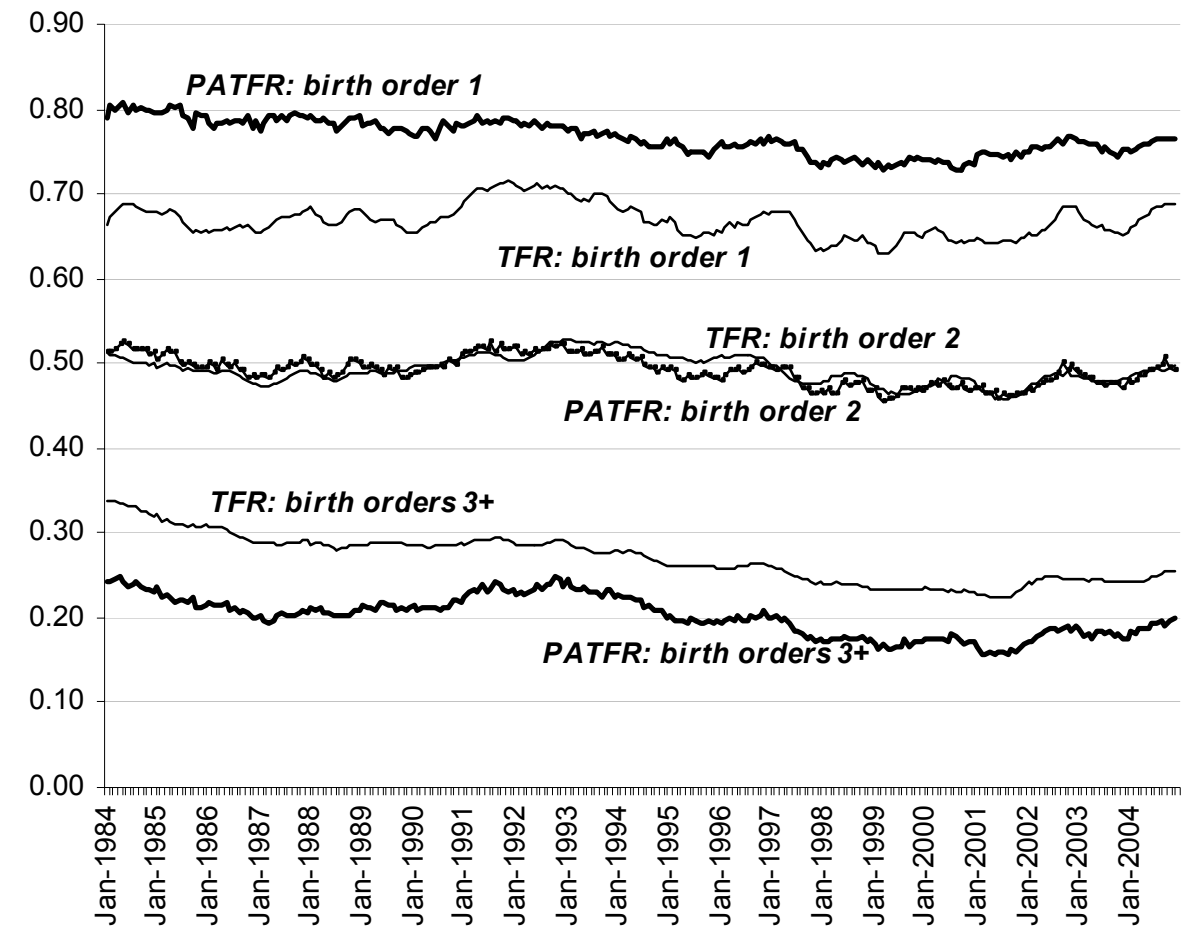

Note: There is a discontinuity in the estimations of the PATFR between December 2000 and January 2001 (see footnote 15 and Appendix 5).

15 There is a minor discontinuity in the estimated PATFR index between December 2000 and January 2001: the data on age-parity distribution of the female population for the period through 2000 were primarily based on the 1991 Census results, whereas the data for 2001-2004 were primarily based on the 2001 Census results. Appendix 5 shows that the differences between these two estimates are very minor and concern mostly first births. 
that during the last two decades the first-order fertility quantum has remained well above the levels suggested by the period total fertility rates.

The results differ, however, for higher birth orders. The PATFR index is particularly strongly affected by the changes in fertility timing at order 3 and above. For birth order 2, both indicators show very similar values and almost identical trends, while the PATFR stays well below the period TFR at birth orders 3 and higher. Obviously, the PATFR is also affected by the changes in fertility timing, but unlike the TFR, the extent of the tempo distortions is strongly linked with parity: the higher the parity, the more pronounced the tempo effects in the PATFR. This pattern, reflecting strong negative effects of 'fertility ageing' in the age-parity fertility model was also found for other European countries (Sobotka 2004a); we discuss it briefly in Section 8. All birth orders combined, the PATFR index typically remains slightly above the TFR (Figure 7 below), but this difference is so small that it does not justify the use of the PATFR as a substitution for the total fertility rate.

\subsection{Parity Progression Ratios Based on Duration since Previous Birth (PPRd)}

Figure 5 presents period parity progression ratios among women with one, two, and three children. It features two different indicators based on birth interval (duration) from previous birth, introduced in Section 4.2: parity progression ratio based on duration-specific incidence rates (PPRdIR), computed for the whole analysed period and the indicator based on duration-parity birth probabilities $(P P R d)$ for the period starting in 1999. These two indicators differ appreciably only in the case of the progression from first to second birth, where the PPRd indicates smoother trends and slightly higher values. For the period between 1999 and 2004, the progression rate to another child among women at parity 1 was 0.717 when analysed with the duration 'incidence rates' PPRdIR and 0.752 when measured with the life table indicator PPRd.

Progression rates to higher-order births, not shown here, are very close to the progression rate from parity three to four and are relatively unstable due to the small number of monthly births. The figure illustrates well the persistent popularity of a two-child family model: while the progression rate to the second child remains close to three quarters, less than $40 \%$ of women with two children eventually have a third child. There is a marked upward trend between 1987 and 1992 in the propensity to have a second and a third child. This trend culminated in January 1993, when the parity progression from the first to the second child (PPRdIR) reached 0.81, up from 0.68 recorded in the first quarter of 1987. Between 1993 and 1999, the progression rate towards the second and the third child gradually declined. More recently, the progression to a second, third as well as fourth child has been increasing again: among women with one child, the 
Figure 5:

Period parity progression ratios based on duration-parity incidence rates (PPRdIR) and duration-parity birth probabilities (PPRd), 1984-2004

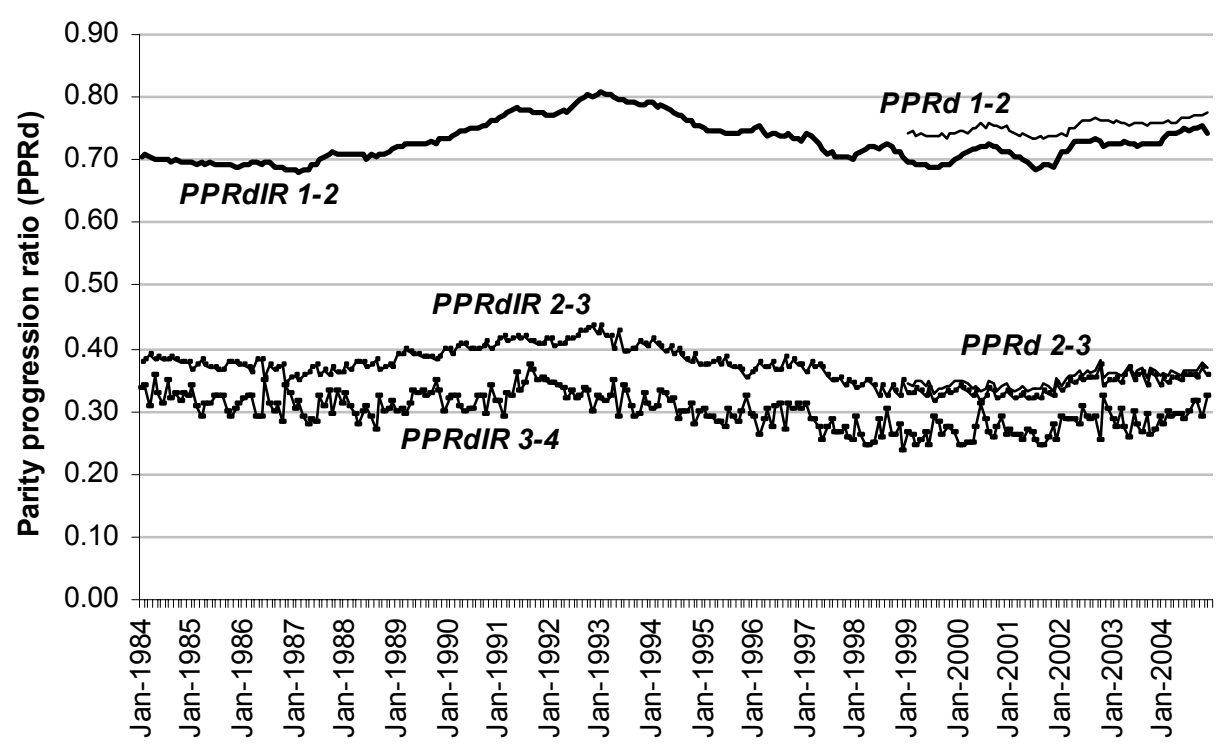

parity progression rate based on incidence rates reached 0.75 in the second half of 2004, which represents the highest level since 1996 (see also Section 7).

Are the duration-based $P P R$ suitable indicators of fertility quantum? Unlike the total fertility rate, the PPRd indicators are not affected by the general shift towards delayed parenthood. Assuming that there is no 'fertility ageing effect,' and the shift to later childbearing does not considerably affect fertility intensities, the $P P R$ framework provides a reliable measure of fertility quantum in a longer time perspective (see also Section 8). ${ }^{16}$ However, the period PPRd may be distorted by tempo effects related to the shortening or prolonging birth intervals. The peak in parity progression ratios in 1992-1993 might be caused by a temporary 'speeding-up' of childbearing among women who already had one child. Nevertheless the evidence suggests that the recorded increase in the intensity of childbearing was genuine - manifested also by a slight increase in the TFR as shown in Figures 2 and 7.

16 This feature is reflected by a close correspondence between the period PPRd indicator and its cohort counterpart. The latter can be computed not only for birth cohorts of women, but also for the parity cohorts of women who had their first, second, or higher-order child in a particular year. Our computations for these parity cohorts in Austria show that the progression rate to a second child is surprisingly stable and thus far unaffected by later childbearing, reaching eventually the levels of 0.72-0.77 among women giving birth to their first child in 1984 and later. This corresponds to the mean value of the period PPRdIR indicators between 1984 and November 2004, which reached 0.73 . 
Although Hoem, Prskawetz, and Neyer (2001) found evidence of a shortening birth interval between the second and third child in 1993-1996 following the change in parental leave regulations effective from July 1990, our data suggest that the mean birth intervals have remained stable since the mid-1980s. The mean interval between the first and second births is 4.0 years, while women who chose to have a third child wait longer, 5.0 years on average (see Figure 6). This stability of birth intervals lends support to our assumption that in the case of Austria the duration-based parity progression ratios are generally undistorted by tempo effects and represent the period fertility quantum quite well.

\section{Figure 6:}

Mean birth intervals, 1984-1994 (3-month moving averages)

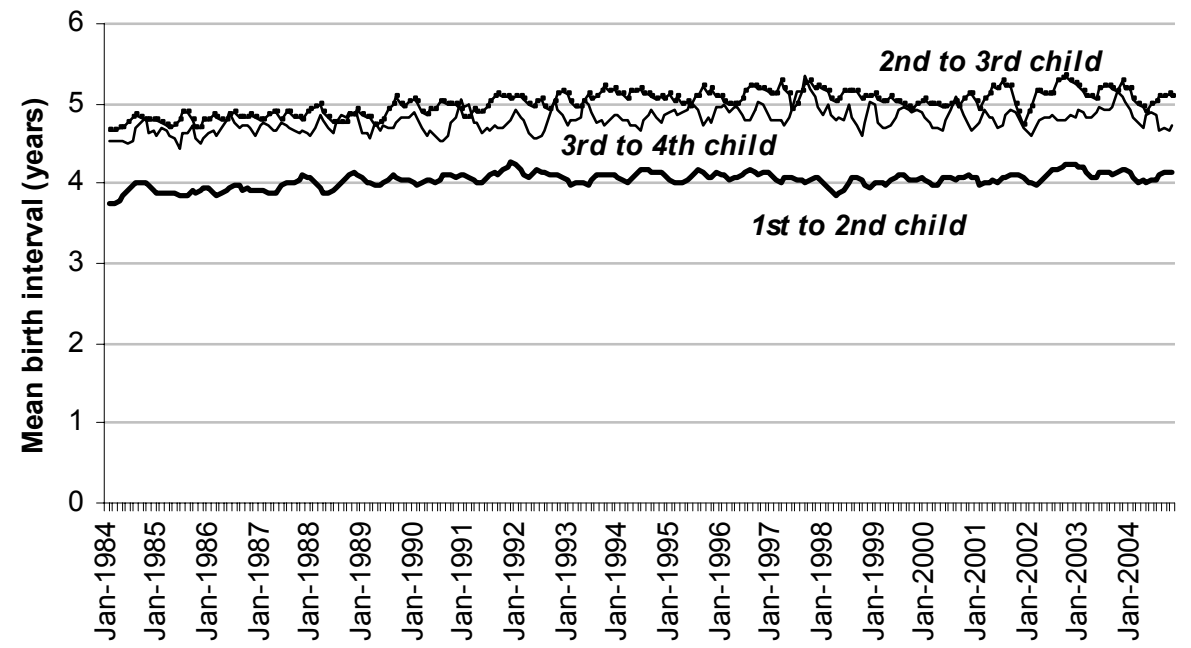

\subsection{The Period Average Parity (PAP)}

The index of the period average parity $(P A P)$, derived from a combination of the $P A T F R$ for birth order 1 with the duration-based parity progression ratios, is compared with the TFR and the PATFR in Figure 7. For the period of 1999-2004, two different values are shown: the period average parity constructed from the duration-specific incidence rates (PAP-rates) and another, based on durationparity birth probabilities for women at parities 1 and higher $(P A P)$. Similar to the findings on progression rates among women at parity 1 , the fertility table $P A P$ indicates a slightly higher level of fertility quantum than its 'incidence rates' 
counterpart. However, the difference between them is narrow in comparison with the other two indicators considered ${ }^{17}$ and both depict identical trends over time.

Thanks to its limited sensitivity to the tempo distortions, the $P A P$ shows considerably higher levels of period fertility than both the TFR and the PATFR. The distance between the PAP-rates indicator on the one hand and the TFR and the PATFR on the other remained fairly wide during the whole period between 1984 and 2004. Surprisingly, all three indicators show almost identical trends marked by short-term fluctuations as well as several more lasting shifts: the rise in fertility, peaking in 1991-1993, a subsequent gradual decline followed by a trough in 1999-2001 and a recent upward trend. The elevated fertility levels around 1992 were more pronounced in the PAP-rates index, suggesting that the timing effects did not diminish during that period: whereas the calendar and seasonally adjusted TFR reached 1.54 in the mid-1991, the PAP reached a level of 1.78 at the same time.

\section{Figure 7:}

Monthly series of the synthetic indicators of total fertility: $P A P$ based on duration incidence rates (PAP-rates) and birth probabilities $(P A P), P A T F R$, and TFR in 19842004

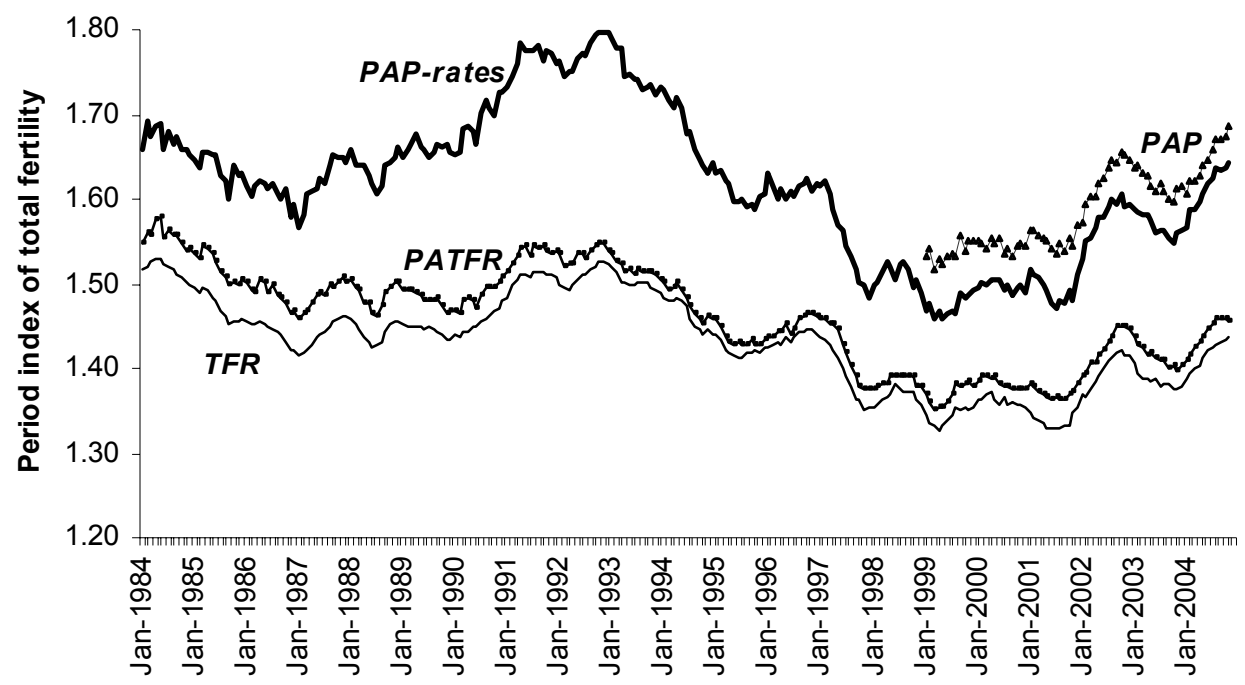

7 The average value of the PAP-rates in 1999-2004 was 1.54 as compared with the average level of 1.60 reached by the $P A P$. 


\section{Analysing Short-term Movements in Period Fertility: 2001-2004}

The main purpose of our investigation is to construct fertility indicators that allow to trace and analyse short-term trends in period fertility rates. The recent upswing in period fertility, originating in 2001, may serve as an example of change that can be studied with the monthly series of the TFR and $P A P$ indicators. Although we analyse order-specific components of both indicators, we focus particularly on parity progression ratios and the $P A P$ index constructed from duration-parity birth probabilities.

The recent fertility increase has occurred in two waves. During the first wave, fertility increased between November 2001 and August 2002. The PAP index grew by $7 \%$, from 1.54 to 1.65 . Subsequently, fertility was slightly declining for about a year, when the $P A P$ reached a low level of 1.60 in September-October 2003. Then, fertility started to rise again, peaking at 1.68 in November 2004, representing an increase of $9 \%$ over the whole 3 -year period since November 2001. Considering the timing of conception rather than the actual timing of births, we may conclude that pregnancy rates increased for most of the years 2001 and 2003, starting in the February-March period. Relative changes in the total fertility rate have been almost identical; overall, the $T F R$ has risen by $8 \%$ during the last three years, from 1.33 in October 2001 to 1.44 in November 2004. The most recent data for November 2004 show that the fertility level has been the highest since the mid-1990s. The increase in the PAP index points out that the recent rise in fertility is due to a 'genuine' increase in fertility quantum and has not been driven by a decline in tempo distortions. The estimated tempo effect, as represented by a difference between the $P A P$ and the TFR, has remained stable since 2001 .

What has been the role of order-specific components? In absolute terms, almost half the increase in total fertility has been driven by an increase in its firstorder component, corresponding to its share on the TFR. More interesting is an analysis of relative changes in order-specific components of the TFR and PAP, revealing a rapidly rising propensity to have a child among women with two or more children, especially between October 2001 and July 2002 and, most recently, since April 2004. Whereas in November 2004 the TFR exceeded by 7\% the level reached in January 2001, the TFR for birth orders $3+$ increased by $12 \%$ (see Figure 8). However, due to the low share of higher-order births on the overall $T F R$, the absolute impact of this increase was limited. The increase in higherorder fertility rates is even more pronounced in the decomposition of the PAP. This indicator suggests that the increase in fertility was mostly driven by the rising propensity of mothers with one or more children to have another child. Whereas the PATFR for first birth order increased only by $2 \%$ between January 2001 and November 2004, the $P A P$ index for orders $3+$ shot up by about $27 \%$. 
Figure 8:

Relative changes in the TFR and $P A P($ total and for birth orders $3+$ ) between January 2001 and November 2004; January 2001=100

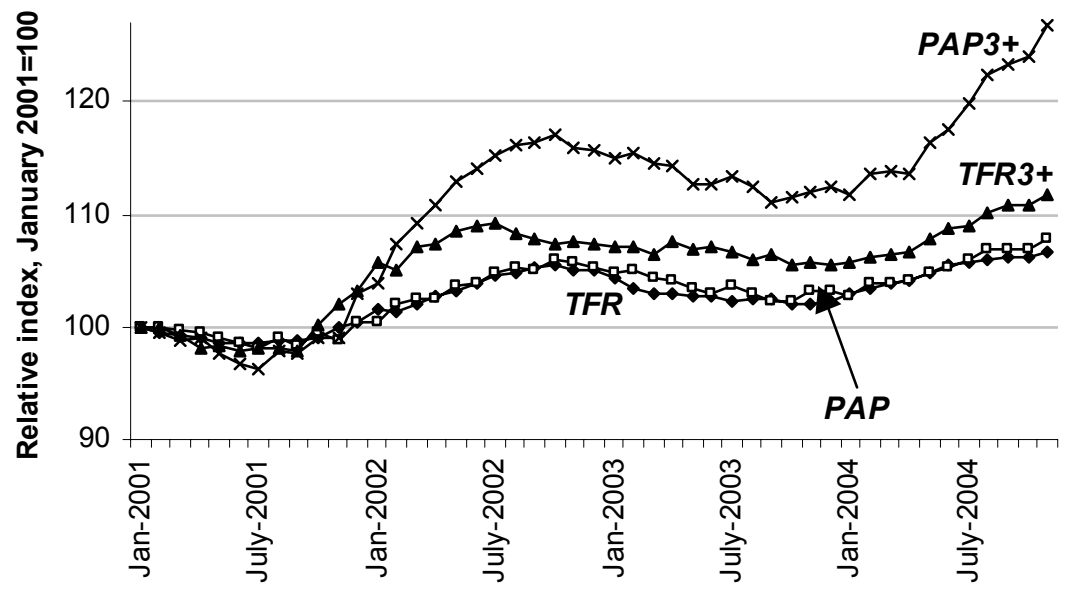

Note: PAP index is based on duration-parity birth probabilities.

Despite considerable differences between the TFR and $P A P$, the relative increase in fertility among women with two or more children is well detected by both indicators. When the timing of conception is considered, the steeper part of this increase can be traced back to the period between January (or March when measured with the parity progression data) to October 2001. The decomposition of change in parity-progression ratios PPRd between October-November 2001 and October-November 2004, summarised in Table 1, further shows that the propensity to have another child increased with parity. Childless women were only by $3 \%$ more likely to bear a child in the latter period, while the propensity to have an additional child increased by 5\% among women with one child, $11 \%$ among women with two children and 13\% among women with 3 children as compared with the overall increase of $8 \%$ in the $P A P$ index.

However, the probabilities of not progressing to another child, $q_{i}$, offer another interpretation of recent fertility changes: whereas the relative increase in the progression rates to another child was more intensive at higher birth orders, the probability of remaining at a given parity has declined especially for women at parity 1 (Table 1). Thus, the recent rise in Austrian fertility implies that the dominant 2-child family norm has been further reinforced. Furthermore, increasing fertility rates at third and higher order mark a clear trend reversal: from the late 1960s until the late $1990 \mathrm{~s}$, period fertility trends were dominantly driven by a declining fertility at higher birth orders, initially steep, and later gradual. This decline has now come to an end and, in the last two years, has been reversed. 
Although it appears robust, it is too early to tell whether this reversal might last in the coming years.

Table 1:

Parity progression ratios $(P P R), P A P$ index, and the probabilities of not progressing to higher parity $\left(q_{i}\right)$ in October-November 2001 and October-November 2004

\begin{tabular}{|c|c|c|c|c|c|c|c|c|}
\hline & \multicolumn{4}{|c|}{ Parity progression ratios } & \multicolumn{3}{|c|}{$\begin{array}{l}\text { Prop. not progressing to } \\
\text { higher parity }\end{array}$} & \multirow[b]{2}{*}{ PAP } \\
\hline & $\mathrm{PPR}_{01}$ & $\mathrm{PPR}_{12}$ & $\mathrm{PPR}_{23}$ & $\mathrm{PPR}_{34}$ & $\mathrm{q} 1$ & $\mathrm{q} 2$ & $\mathrm{q} 3$ & \\
\hline $\begin{array}{l}\text { October to November } \\
2001\end{array}$ & 0.745 & 0.737 & 0.336 & 0.274 & 0.263 & 0.664 & 0.726 & 1.549 \\
\hline $\begin{array}{l}\text { October to November } \\
2004\end{array}$ & 0.764 & 0.774 & 0.372 & 0.308 & 0.226 & 0.628 & 0.692 & 1.679 \\
\hline Index 2004/2001 & 1.03 & 1.05 & 1.11 & 1.13 & 0.86 & 0.95 & 0.95 & 1.08 \\
\hline Abs. change 2001- 04 & 0.020 & 0.037 & 0.036 & 0.034 & -0.037 & -0.036 & -0.034 & 0.130 \\
\hline
\end{tabular}

Notes: PPR0-1 is equal to the PATFR index of birth order one.

$P A P$, parity progression ratios $P P R$, and the probabilities of not progressing to another parity are computed from duration-parity birth probabilities.

\section{Discussion: The Advantages and Possible Drawbacks of the Period Average Parity}

Do duration-based parity progression ratios and the aggregate period average parity indeed constitute an unambiguous measure of fertility quantum during the periods of intensive shifts in fertility timing? Their use can be contested for four main reasons:

The first, and in our view the most serious one, is not related to the characteristics of these indicators, but to our estimations of the number of women by parity and year of previous birth. By not accounting for migration, we have most probably underestimated the size of the 'exposure population' and inflated thus slightly the resulting fertility indicators (see Appendix 2, Section A-2.5). This problem can be overcome when large-scale survey data are used (as in the study of French data by Rallu and Toulemon 1994 and Toulemon 2001) or when the information on migrant women contains the number of their children ever born and the date (year) at giving last birth.

The second possible objection to the PAP and PPRd concerns their assumption of no 'fertility ageing effect.' Later age at first birth is usually associated with lower progression rates to additional births, an effect termed by Kohler and Ortega (2002) 'postponement-quantum interaction.' This interaction is incorporated in the age-parity fertility model (PATFR; see Section 6.2). However, the strong negative effects of fertility postponement on higher-order fertility in the age-parity fertility model could also be seen as spurious: for any given period, the age-parity framework links together in a sequential way fertility of different parity 
cohorts that experienced different patterns of the timing of family formation in the past. The extent to what the overall shift to later childbearing affects fertility quantum is context-specific and, in some cases, there might be no perceptible effect of the later timing of childbearing on the ultimate fertility quantum. Toulemon and Mazuy (2001, Figure 2 in Annex) have shown that despite the increase in the mean age at first and second birth, parity progression ratios among women at parity 1 and 2 have remained remarkably stable in France. Our data indicate a similar stability for the progression from first to second birth in Austria.

Third, the $P A P$ is not entirely free of tempo effects as its first-order component is based on the (unadjusted) age-parity fertility table indicator PATFR, which is to some extent affected by the changes in fertility timing. However, in comparison with the commonly used TFR, the PAP consistently indicates higher levels of period fertility quantum in Austria during the entire period since 1984. The $P A P$ based on incidence rates suggests that the period total fertility rates in Austria in 1985-2003 had been 'deflated' by 0.19 on average by the ongoing trend towards later timing of childbearing (see Table AN-1 in Annex). Its mean level in this period (1.62) converges with our estimates of the annual mean values of the Kohler-Ortega adjusted PATFR index (1.61). ${ }^{18}$ Our analysis indicates that if the $P A P$ were entirely free of tempo effects, its level would probably come close to 1.70 (see Appendix 6). Even this estimate implies that by using the $P A P$ at least two thirds of the tempo effects present in the TFR can be eliminated. Thus, the $P A P$ provides a considerably better estimate of the period fertility quantum than the conventional indicators.

Finally, our favourable assessment on the $P A P$ index hinges upon the validity of its underlying assumption concerning the relative stability of the mean birth intervals in the duration-based parity progression ratios. This assumption was supported in the case of Austrian data (see Section 6.3), but might be violated in other cases.

Certainly the $P A P$ should also be evaluated with the data for other countries and regions, especially those that have experienced more pronounced changes in fertility. Further dissemination of the $P A P$ indicator is constrained by limited availability of detailed data on births by birth order and duration since the previous birth, which are not routinely published by the official statistical bodies. We are nevertheless convinced that the $P A P$ has a strong potential and deserves widespread use in other countries experiencing rapid fertility postponement. The eventual ending up of fertility postponement is likely to be associated with a modest increase in the period TFR in Austria and many other European countries. The use of the $P A P$ index could help distinguish between the 'genuine' increase in period fertility and the increase related to the ending of the tempo distortions in the period TFR.

18 Recall that our estimates of Kohler-Ortega adjusted PATFR contain adjusted fertility only for birth orders 1 and 2, whereas the fertility rate at orders $3+$ is based on a conventional TFR (see Appendix 3, Section A-3.6). 


\section{Conclusion}

This study utilised a database of individual birth records in Austria to find out whether we can derive monthly indicators of fertility that minimise the distortions caused by the shifts in the timing of childbearing. We have shown that in order to derive meaningful indicators of monthly fertility, the raw data should be adjusted for seasonality and the trend component. Since the seasonal childbearing patterns differ by birth order, it is useful to differentiate the seasonal adjustment by birth order as well. Considering a finer level of detail by using indicators computed for monthly birth cohorts instead of the usual year-cohort format did not appreciably change any of the fertility indicators computed. Our focus on period fertility indicators that are parity-specific (i.e., they correctly reflect exposure) and may at the same time reduce the magnitude of tempo distortions proved fruitful. The "period average parity" $(P A P)$ provides a realistic estimate of fertility quantum and constitutes a methodologically sound indicator based on a duration-parity fertility table model. Out of the two different estimates of the PAP presented here for the period starting in 1999-one based on duration and order-specific incidence rates and another on duration-parity birth probabilities - the latter indicates slightly higher values of fertility quantum. Although it is methodologically preferable to the 'incidence rates' model and arguably also provides more robust results, our analysis suggests that in the Austrian context both indicators can be used to a large extent interchangeably for depicting recent trends and levels of the total fertility quantum.

Our study has illustrated the usefulness of analysing monthly fertility changes, even in a country like Austria, where the long-term fertility trends since the mid1980s remained stable when compared with most other European countries. Monthly data contribute to a better understanding of fertility decision making of couples and allow for a more precise interpretation of fertility trends in conjunction with relevant social and economic trends and policy measures. Our analysis brings important insights into the recent increase in Austrian fertility, detectable since the last months of 2001, which has been more pronounced among mothers with two or more children. This suggests the possibility that it was partly related to the extension of the period of paid parental leave ("Kindergeld") and the broader eligibility for mothers and fathers to receive the leave, proposed by the government in April 2001 and in effect since January 2002 (Gisser and Fliegenschnee 2004). Whether the recent stabilisation and subsequent increase in fertility at third and higher birth orders marks a trend reversal or rather constitutes a short-time fluctuation remains yet unknown.

Our research has also a practical outcome that makes it possible to keep our eye on these recent trends: in collaboration with Statistics Austria, which will regularly supply us with the most recent data on births, we will establish a continually updated monitoring system and regularly publish the most recent indicators of monthly period fertility. This constitutes a significant improvement 
to the current practice of regular reporting of monthly total births which have just been compared with the total births recorded during the same month or period in the previous year.

The theoretical and methodological discussion regarding the interpretation of different period fertility indicators as well as the issue of tempo effects is still in full swing. From this perspective, the analysis presented in this paper may stimulate further debates as it contributes to this discussion and to further methodological advancement in fertility research.

\section{Acknowledgements}

This article is a result of our work on the project "Birth Barometer" (Geburtenbarometer), supported by the Austrian Federal Ministry of Social Security, Generations and Consumer Protection (Bundesministerium für Soziale Sicherheit, Generationen und Konsumentenschutz), grant number BMSG442030/006-V7/2004. We gratefully acknowledge the assistance provided by Statistics Austria in acquiring the data on births used in our analyses. A previous draft was published as a Working Paper at the Vienna Institute of Demography (Sobotka et. al. 2005). We would like to thank Werner Richter for his careful editing of the text and two anonymous reviewers for many helpful comments.

\section{References $^{19}$}

Barkalov, N. B. and J. Dorbritz. 1996. "Measuring parity-progression ratios with competing techniques. An application to East Germany." Zeitschrift für Bevölkerungswissenschaft 21(4): 459-505.

Bobak, M. and A. Gjonca. 2001. "The seasonality of live birth is strongly influenced by sociodemographic factors." Human Reproduction 16(7): 1512-1517.

Bongaarts, J. 2002. "The end of the fertility transition in the developed world." Population and Development Review 28(3): 419-443.

Bongaarts, J. and G. Feeney. 1998. "On the quantum and tempo of fertility." Population and Development Review 24(2): 271-291.

Brass, W. 1991. Cohort and time period measures of quantum fertility: Concepts and methodology. In.: Becker, H. A. (Ed.). Life histories and generations. University of Utrecht, ISOR, pp. 455-476.

Calot, G. 1981a. L'observation de la fécondité à court et moyen terme. Population 36(1): $9-40$.

19 The reference list also contains references to the literature cited in Appendices. 
Calot, G. 1981b. Le mouvement journalier des naissances à l'intérieur de la semaine. Population 36(3): 477-504.

Calot, G. and Nadot. 1977. “Combien y aura-t-il de naissances dans l'année?” Population 32 (numero special): 185-229.

Cottrel, A. 2004. Gnu Regression, Econometrics and Time-series Library - Gretl. Accessed at «http://gretl.sourceforge.net».

David, H. P. 1970. Family planning and abortion in the socialist countries of Central and Eastern Europe. New York, The Population Council.

David, H. P. (Ed.). 1999. From abortion to contraception. A resource to public policies and reproductive behavior in Central and Eastern Europe from 1917 to the present. Westport, Connecticut, Greenwood Press.

Doblhammer-Reiter, G, J. L. Rodgers, and R. Rau. 1999. "Seasonality of birth in nineteenth and twentieth century Austria: Steps toward a unified theory of human reproductive seasonality.”. MPIDR Working Paper WP 1999-013, Max Planck Institute for Demographic Research, Rostock. Accessed at «http://www.demogr.mpg.de/Papers/ Working/WP-1999-013.pdf».

EUROSTAT. 2004. NewCronos database. Theme 3: Population and social conditions. Accessed in October 2004. « http://epp.eurostat.cec.eu.int»

Feeney, G and J. Yu. 1987. "Period parity progression measures of fertility in China." Population Studies 41(1): 77-102.

Findley, D. F., B. C. Monsell, W. R. Bell, M. C. Otto, and B. Chen. 1998. "New capabilities and methods of the X-12-ARIMA seasonal adjustment program." Journal of Business and Economic Statistics 16: 127-177.

Frejka, T. and G. Calot. 2001a. "Cohort childbearing age patterns in low-fertility countries in the late $20^{\text {th }}$ century: Is the postponement of births an inherent element?" MPIDR Working Paper WP 2001-009, Max Planck Institute for Demographic Research, Rostock. «http://www.demogr.mpg.de/Papers/Working/wp-2001-009.pdf».

Gisser, R. and K. Fliegenschnee. 2004. Country report on general family-related policies and attitudes."Vienna Institute of Demography, internal paper, August 2004.

Gisser, R. 1984. Geborene und Gestorbene 1982. Statistische Nachrichten 39(3): 148-151.

Goldstein, J., W. Lutz, and S. Scherbov. 2003. "Long-term population decline in Europe: The relative importance of tempo-effects and generational length." Population and Development Review 29(4): 699-707.

Haandrikman, K. 2004. "Seizonfluctuaties in geboorten: veranderte patronen door planning?" Bevolkingstrends, 2004(4): 14-22.

Hajnal, J. 1947. "The analysis of birth statistics in the light of the recent international recovery of the birth-rate." Population Studies 1(2): 137-164.

Henry, L. 1961. "Un nouveau tableau statistique: Les naissances suivant le rang et l'année de naissance de l'enfant precedent." Population 16(3): 513-515.

Henry, L. 1953. "Fécondité des mariages. Nouvelle méthode de mesure" Travaux et Documents no. 16, INED-PUF, Paris.

Hoem, J M., A Prskawetz, and G. Neyer. 2001. Autonomy or conservative adjustment? The effect of public policies and educational attainment on third births in Austria, 1975-96.“ Population Studies 55: 249-261.

Höhn, C. 1981. "Die CALOT-Methode zur aktuellen Beurteilung von Geburtenniveau und -trend." Zeitschrift für Bevölkerungswissenschaft 7(2): 231-254. 
Kohler, H.-P. and J. A. Ortega. 2004. "Old insights and new approaches: Fertility analysis and tempo adjustment in the age-parity model." Vienna Yearbook of Population Research 2004: 57-89.

Kohler, H.-P. and J. A. Ortega. 2002. "Tempo-adjusted period parity progression measures, fertility postponement and completed cohort fertility." Demographic Research 6, Article 6: 92-144. «www.demographic-research.org».

Kohler, H.-P. and D. Philipov. 2001. "Variance effects in the Bongaarts-Feeney formula." Demography 38(1): 1-16.

Kohler, H.-P., F. C. Billari, and J. A. Ortega. 2002. "The emergence of lowest-low fertility in Europe during the 1990s". Population and Development Review 28(4): 641-680.

Ladiray, D. and B. Quenneville. 2001. Seasonal adjustments with the X-11 method. Lecture notes on Statistics, New York: Springer.

Lam, D. A., J. A. Miron, and A. Riley. 1994. "Modelling seasonality in fecundability, conceptions, and births." Demography 31(2): 321-346.

Lesthaeghe, R. 2001. "Postponement and recuperation: Recent fertility trends and forecasts in six Western European countries." Paper presented at the IUSSP Seminar "International perspectives on low fertility: Trends, theories and policies", Tokyo, 2123 March 2001. Accessed at «demography.anu.edu.au/Virtual Library/ ConferencePapers/ IUSSP2001/».

Lesthaeghe, R. and P. Willems. 1999. "Is low fertility a temporary phenomenon in the European Union?" Population and Development Review 25(2): 211-228.

Lutz, W. 1989. Distributional aspects of human fertility: A global comparative study. Academic Press, Harcourt Brace Jovanovich, Publishers, London.

Lutz, W., B. C. O'Neill, and S. Scherbov. 2003. "Europe's population at a turning point." Science 299: 1991-1992.

Miller and Williams. 2004. "Damping seasonal factors: shrinkage estimators for the X12-ARIMA program.” International Journal of Forecasting 20: 529-549.

Ní Bhrolcháin, M. and L. Toulemon. 2003. "The trend to later childbearing: is there evidence of postponement?" SSRC Applications and policy Working Paper A03/10, Social Statistics Research Centre, University of Southampton. Accessed at: «http://www.s3ri.soton.ac.uk/publications/papers-applications/ssrc-workingpapera03-10.pdf».

ONS. 2004. Birth statistics. Review of the Registrar General on births and patterns of family building in England and Wales, 2003. Series FM1, no. 32, Office of National Statistics, London. «www.statistics.gov.uk/downloads/theme_population/FM1_32/ FM1no32.pdf».

Philipov, D. and H.-P. Kohler. 2001. "Tempo effects in the fertility decline in Eastern Europe: Evidence from Bulgaria, the Czech Republic, Hungary, Poland and Russia". European Journal of Population 17(1): 37-60.

Prioux, F. 1988. "Mouvement saisonnier des naissances." Population 43(3): 587-610.

Rallu, L. and L. Toulemon. 1994. "Period fertility measures. The construction of different indices and their application to France, 1946-89". Population, An English Selection, 6: 59-94.

Ryder, N. 1980. "Components of temporal variations in American fertility". In: R. W. Hiorns (Ed.) Demographic patterns in developed societies, Symposia of the Society for the Study of Human Biology, Vol. XIX, Taylor \& Francis Ltd., London, pp. 15-54. 
Sardon, J.-P. 1998. "Fécondité, bouleversements politiques et transition vers l'économie de marché en Europe de l'Est". Espace, Populations, Sociétés 1998-3: 339-360.

Schoen, R. 2004. "Timing effects and the interpretation of period fertility". Demography 41(4): 801-819.

Smallwood, S. 2002. "The effect of changes in timing of childbearing on measuring fertility in England and Wales". Population Trends, No. 109: 36-45. Accessed at «www.statistics.gov.uk/statbase/Product.asp?vlnk=6303».

Sobotka, T. 2004a. Postponement of childbearing and low fertility in Europe. Doctoral thesis, University of Groningen. Amsterdam: Dutch University Press.

Sobotka, T. 2004b. "Is lowest-low fertility explained by the postponement of childbearing?" Population and Development Review 30(2): 195-220.

Sobotka, T., M. W. Dworak, M. Rita Testa, W. Lutz, D. Philipov, H. Engelhardt, and R. Gisser. 2005. "Monthly Estimates of the Quantum of Fertility: Towards a Fertility Monitoring System in Austria." VID Working Papers 01/2005. Vienna: Vienna Institute of Demography. «http://www.oeaw.ac.at/vid/publications/WP2005_1.pdf».

StataCorp. 2004. Stata Stastical Software: Release 8.2. College Station, TX: Stata Corporation.

Statistics Austria. 2005. Volkszählung 2001. Haushalte und Familien. Statistics Austria, Wien.

Statistics Austria. 1996. Volkszählung 1991. Haushalte und Familien. Herausgegeben vom Österreichischen Statistischen Zentralamt 1.030/26. Heft, Wien.

Statistics Austria. 1989. Volkszählung 1981. Eheschließungs- und Geburtenstatistik. Herausgegeben vom Österreichischen Statistischen Zentralam, Heft 630/27, Wien

Stier, Winfried. 2001. Methoden der Zeitreihenanalyse. Berlin: Springer.

Toulemon, L. 2001. Why fertility is not so low in France? Paper presented at the IUSSP Meeting "International perspectives on low fertility: Trends, theories and policies," Tokyo, 21-23 March 2001.

Toulemon, L. 2004. Cohort fertility analysis and population projections. Presentation at the United Nations, New York, 22-24 April 2004.

Toulemon, L. and M. Mazuy. 2001. "Les naissances sont retardées mais la fécondité est stable". Population 56(4): 611-644.

Van Imhoff, E. 2001. "On the impossibility of inferring cohort fertility measures from period fertility measures". Demographic Research 5, Article 2: 23-64. «Www.demographic-research.org».

Van Imhoff, E. and N. Keilman. 2000. "On the quantum and tempo of fertility: Comment". Population and Development Review 26(3): 549-553.

Yamaguchi, K. and M. Beppu. 2004. "Survival probability indices of period total fertility rate”. Discussion Paper Series 2004-01, The Population Research Centre, NORC \& The University of Chicago. Accessed in March 2004 at «http://www.src.uchicago.edu/pre/pdfs/yamagu04.pdf». 


\section{ANNEX}

Figure AN-1:

Mean age at childbearing by birth order in 1984-2004

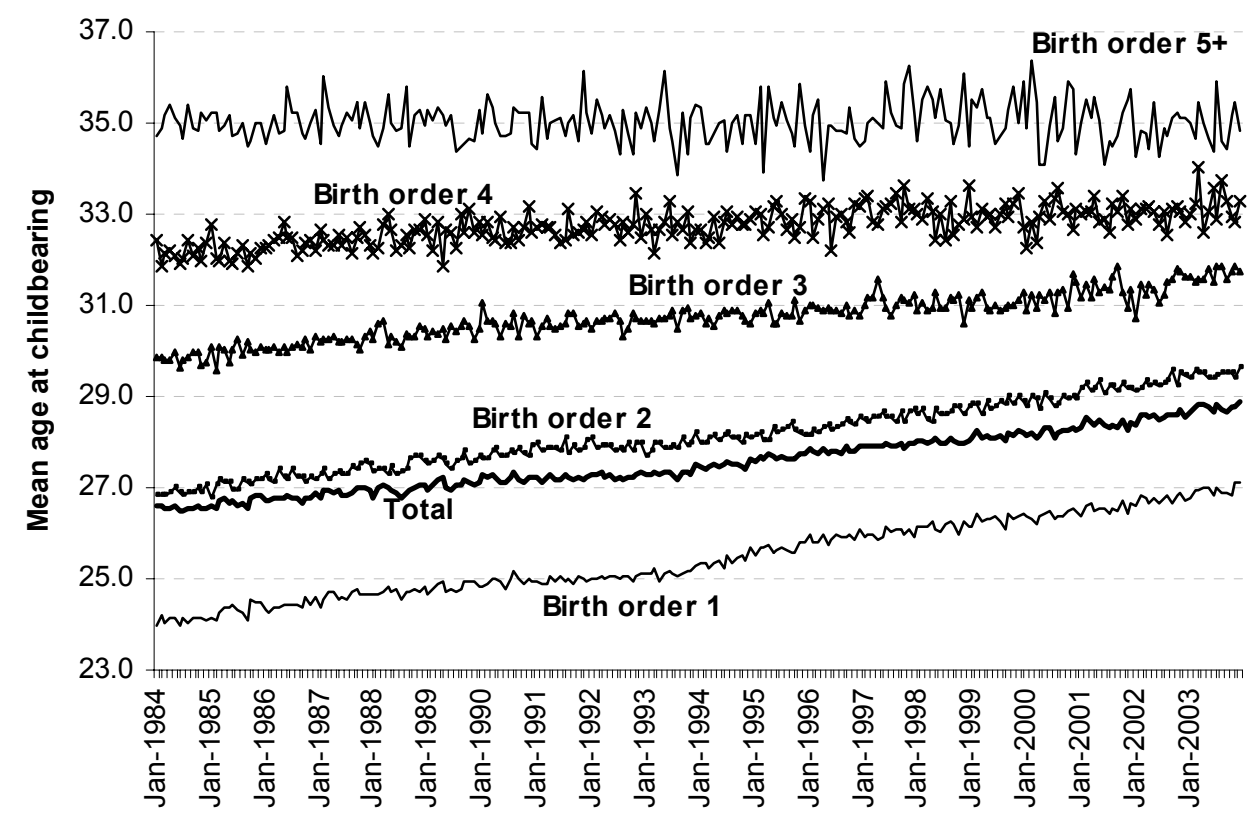

Figure AN-2:

Weekday coefficients of the number of live births by parity in 2003

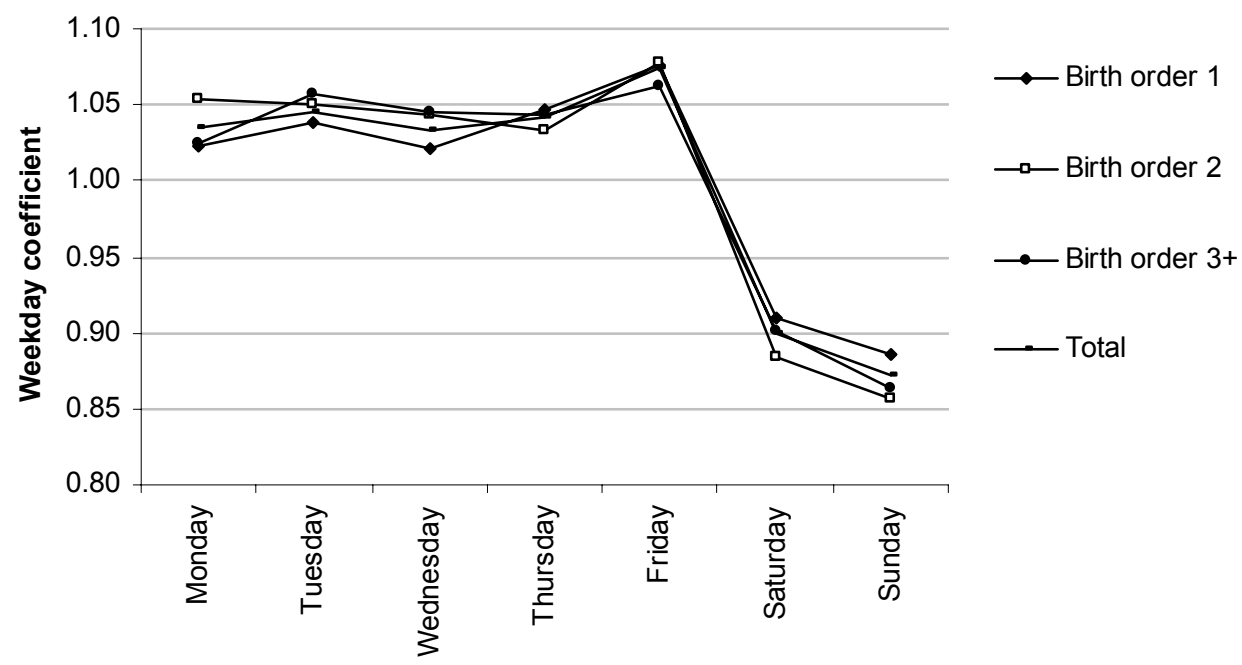


Figure AN-3:

Seasonal coefficients based on the monthly number of births from January 1984 to November 2004

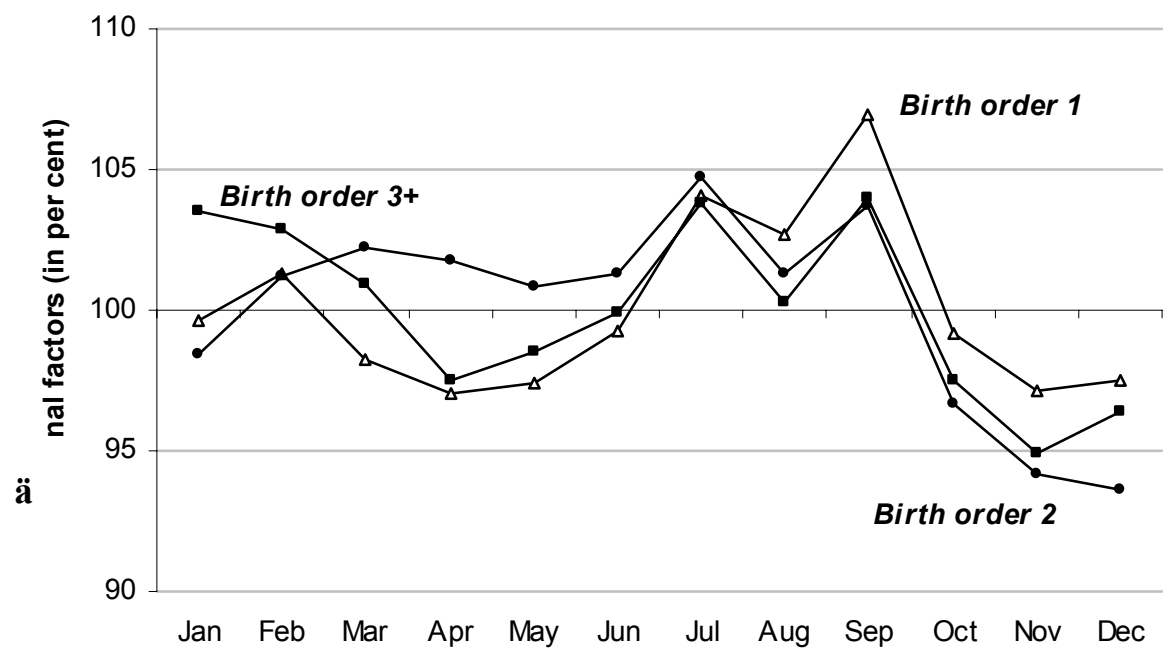

Figure AN-4:

Mean quarterly values of crude (unadjusted) TFR, 1984-2004

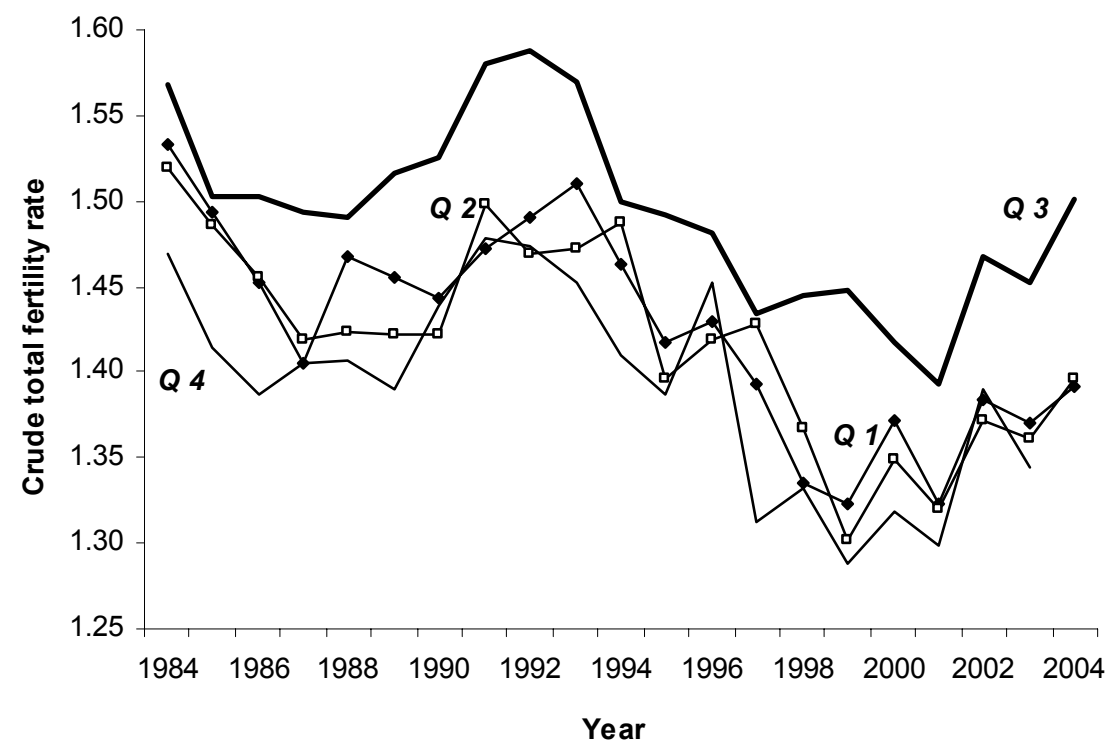


Table AN-1:

Annual values of TFR, PATFR, PAP(rates), PAP, adjPATFR (Kohler-Ortega adjustment), and the estimated size of tempo effects, 1984-2004

\begin{tabular}{|c|c|c|c|c|c|c|c|}
\hline Year & TFR & PATFR & $\begin{array}{l}\text { PAP } \\
\text { (rates) } \\
(3)\end{array}$ & PAP & $\begin{array}{c}\mathrm{KO} \\
\text { adjPATFR } \\
(5)\end{array}$ & $\begin{array}{c}\text { Tempo } \\
\text { effect } \\
(1) \\
(3)-(1)\end{array}$ & $\begin{array}{c}\text { Tempo } \\
\text { effect } \\
(2) \\
(5)-(1)\end{array}$ \\
\hline 1984 & 1.522 & 1.531 & 1.669 & & & 0.147 & .. \\
\hline 1985 & 1.474 & 1.489 & 1.637 & & 1.689 & 0.163 & 0.215 \\
\hline 1986 & 1.449 & 1.466 & 1.608 & & 1.668 & 0.159 & 0.219 \\
\hline 1987 & 1.431 & 1.449 & 1.618 & & 1.635 & 0.187 & 0.204 \\
\hline 1988 & 1.447 & 1.468 & 1.635 & & 1.601 & 0.188 & 0.154 \\
\hline 1989 & 1.446 & 1.466 & 1.659 & & 1.654 & 0.213 & 0.208 \\
\hline 1990 & 1.457 & 1.479 & 1.691 & & 1.612 & 0.234 & 0.155 \\
\hline 1991 & 1.507 & 1.533 & 1.766 & & 1.605 & 0.259 & 0.098 \\
\hline 1992 & 1.505 & 1.527 & 1.773 & & 1.603 & 0.268 & 0.098 \\
\hline 1993 & 1.501 & 1.509 & 1.747 & & 1.627 & 0.246 & 0.126 \\
\hline 1994 & 1.465 & 1.464 & 1.680 & & 1.677 & 0.215 & 0.212 \\
\hline 1995 & 1.423 & 1.425 & 1.607 & & 1.630 & 0.184 & 0.207 \\
\hline 1996 & 1.446 & 1.447 & 1.613 & & 1.609 & 0.167 & 0.163 \\
\hline 1997 & 1.392 & 1.403 & 1.554 & & 1.557 & 0.162 & 0.165 \\
\hline 1998 & 1.370 & 1.379 & 1.511 & & 1.529 & 0.141 & 0.159 \\
\hline 1999 & 1.340 & 1.357 & 1.472 & 1.536 & 1.487 & 0.132 & 0.147 \\
\hline 2000 & 1.364 & 1.378 & 1.497 & 1.545 & 1.594 & 0.133 & 0.23 \\
\hline 2001 & 1.334 & 1.358 & 1.494 & 1.552 & 1.651 & 0.160 & 0.317 \\
\hline 2002 & 1.403 & 1.429 & 1.577 & 1.625 & 1.614 & 0.174 & 0.211 \\
\hline 2003 & 1.382 & 1.414 & 1.568 & 1.618 & 1.575 & 0.186 & 0.193 \\
\hline 2004 & 1.419 & 1.447 & $1.611^{1)}$ & $1.648^{1)}$ & .. & 0.192 &.. \\
\hline $\begin{array}{l}\text { Mean value } \\
1985-2003\end{array}$ & 1.428 & 1.444 & 1.616 & & 1.611 & 0.188 & 0.183 \\
\hline \multicolumn{8}{|c|}{$\begin{array}{l}\text { Notes: } \\
T F R, P A T F R \text {, and adjPATFR are computed from the annual data. } \\
P A P \text { and } P A P(\text { rates }) \text { represent mean values of calendar and season-adjusted monthly time series. } \\
\text { The Kohler-Ortega adjustment was computed only for birth orders } 1 \text { and } 2 \text {; the estimate of the adjPATFR index } \\
\text { is based on the adjusted } P A T F R \text { for orders } 1 \text { and } 2 \text { and the conventional TFR for birth orders } 3+\text {. } \\
\text { 1) data refer to the period of January to November } 2004 \text {. }\end{array}$} \\
\hline
\end{tabular}

